\title{
A Low-Cost Approach Using Diatomaceous Earth Biosorbent as Alternative SPME Coating for the Determination of PAHs in Water Samples by GC-MS
}

\author{
Naysla Paulo Reinert ${ }^{1}$, Camila M. S. Vieira ${ }^{1}$, Cristian Berto da Silveira ${ }^{2}$, Dilma Budziak ${ }^{3}$ and \\ Eduardo Carasek 1,*(D) \\ 1 Departamento de Química, Universidade Federal de Santa Catarina, Florianópolis 88040-900, SC, Brazil; \\ nayslareinert@gmail.com (N.P.R.); camilamaiara.vieira@gmail.com (C.M.S.V.) \\ 2 Departamento de Engenharia de Pesca e Ciências Biológicas, Universidade do Estado de Santa Catarina, \\ Laguna, Santa Catarina 88790-000, Brazil; cristian.silveira@udesc.br \\ 3 Departamento de Ciências Naturais e Sociais, Universidade Federal de Santa Catarina, \\ Curitibanos 89520-000, SC, Brazil; dilmabudziak@yahoo.com.br \\ * Correspondence: eduardo.carasek@ufsc.br
}

Received: 10 October 2018; Accepted: 12 November 2018; Published: 20 November 2018

\begin{abstract}
In this study, the use of recycled diatomaceous earth as the extraction phase in solid phase microextraction (SPME) technique for the determination of polycyclic aromatic hydrocarbons (PAHs) in river water samples, with separation/detection performed by gas chromatography-mass spectrometry (GC-MS), is proposed. The optimized extraction conditions are extraction time $70 \mathrm{~min}$ at $80{ }^{\circ} \mathrm{C}$ with no addition of salt. The limits of quantification were close to $0.5 \mu \mathrm{g} \mathrm{L}{ }^{-1}$ with RSD values lower than $25 \%(n=3)$. The linear working range was $0.5 \mu \mathrm{g} \mathrm{L}^{-1}$ to $25 \mu \mathrm{g} \mathrm{L}^{-1}$ for all analytes. The method was applied to samples collected from the Itajaí River (Santa Catarina, Brazil) and the RSD values for repeatability and reproducibility were lower than $15 \%$ and $17 \%$, respectively. The efficiency of the recycled diatomaceous earth fiber was compared with that of commercial fibers and good results were obtained, confirming that this is a promising option to use as the extraction phase in SPME.
\end{abstract}

Keywords: recycled diatomaceous earth; solid phase microextraction; polycyclic aromatic hydrocarbons; gas chromatography-mass spectrometry

\section{Introduction}

Water is an extremely valuable natural resource as it is responsible for maintaining biological, geological and chemical cycles [1,2]. Environmental problems caused by anthropogenic activities are continually increasing and gaining attention worldwide [1]. With population growth and increased industrial activities, ever greater amounts of petroleum-based fossil fuels are being consumed [3]. These fuels contain a class of compounds known as polycyclic aromatic hydrocarbons (PAHs).

PAHs are a group of organic compounds composed of multiple aromatic rings [4]. The formation of these molecules is associated with the incomplete combustion of natural organic materials, for instance, due to volcanoes or the incomplete burning of wood in forest fires, and from anthropogenic sources including industrial processes (e.g., refineries), vehicular emissions [5], cane burning [6], and others [7]. According to the International Agency for Research on Cancer (IARC) and the US EPA (the United States Environmental Protection Agency) PAHs are recognized as persistent environmental pollutants with carcinogenic and mutagenic capacity in humans $[7,8]$. Based on these issues, measures have been taken by governments around the world to monitor the concentrations of compounds that may be harmful to human health, with different standards and regulations being established 
often aimed at ensuring the quality of drinking water [7]. In Brazil, the Ministry of Health regulates waters for human consumption using benzo[a]pyrene as a marker with maximum permitted values of $0.7 \mu \mathrm{g} \mathrm{L}{ }^{-1}$.

The determination of these pollutants generally requires a sample preparation procedure to remove matrix interferents, concentrate the analyte and make the extract compatible with the analytical instrumentation. One of the most commonly used sample preparation techniques is solid-phase microextraction (SPME) $[9,10]$.

SPME was proposed by Pawliszyn et al. in 1990 to overcome the drawbacks of traditional sample preparation techniques such as liquid-liquid extraction and solid phase extraction $[9,10]$. The principle of the technique is the distribution of the analytes between the sample matrix and the sorbent (fiber), combining sampling, isolation and enrichment in a single step [11,12]. SPME fibers are composed of a fused silica or metallic support coated with an extractive phase, for instance, polymethylsiloxane (PDMS), polyacrylate (PA), or other commercially available sorbent [13-16].

In the search for new sorbent materials for SPME, biosorbents have gained prominence in miniaturized techniques because they provide greener, less expensive, renewable, and biodegradable extractive phases. Many of these biosorbents can be found in the environment and consist of macromolecules with different functional groups that can interact with different types of analytes. Our research group has previously used natural sorbents for the determination of organic contaminants using SPME $[17,18]$. Diatomaceous earth is of particular interest as a new biosorbent since it is discarded in large scale as a waste from breweries, where it is used for the clarification and filtration of organic materials and beers [19].

Diatomaceous earth is obtained from sedimentary rocks, originating from fossilized algae belonging to the class Bacillariophyta (diatoms). It is an amorphous mineral, comprised mainly of silica dioxide, of light weight and low molar mass, and its coloration can vary from white to gray. Structurally, diatoms have a hollow cylindrical form of low density and high surface area [20].

In this study the use of diatomaceous earth as an (bio) extractive phase in SPME is explored for the determination of PAHs in river water samples with quantification by gas chromatography coupled to mass spectrometry (GC-MS). The biosorbent was easily adhered onto a NiTi (nitinol) rod using a quick and inexpensive procedure.

\section{Materials and Methods}

\subsection{Reagents and Materials}

Analytical standards of PAHs in a mixture containing acenaphthylene, fluorene, phenanthrene, anthracene, pyrene, benzo[a]anthracene, chrysene, benzo[b]fluoranthene, benzo[k]fluoranthene, and benzo[a]pyrene (Bellefonte, PA, USA) were used to prepare stock solutions of $1 \mathrm{mg} \mathrm{L}^{-1}$ in acetonitrile purchased from J.T. Baker (Mallinckrodt, NJ, USA). The ionic strength was studied using sodium chloride obtained from Synth (São Paulo, SP, Brazil). The ultrapure water used in the experiments was purified in an ultrapure Mega purity system (Billerica, MA, USA). The fiber was prepared using diatomaceous earth with size less than 200 mesh, nitinol rods $(2 \mathrm{~cm}$ length and $0.128 \mathrm{~mm}$ diameter), epoxy glue acquired from Brascola (São Paulo, SP, Brazil), and a heating block from Dist (Florianópolis, SC, Brazil). SPME extractions were carried out in vials of $40 \mathrm{~mL}$ obtained from Supelco (Bellefonte, PA, USA) aided by a thermostatic bath (Lab Companion RW 0525G, Geumcheon-gu, Seoul, Korea) and magnetic stirrers from Dist (Florianópolis, SC, Brazil). Commercial fibers (DVB/Car/PDMS, 50/30 $\mu \mathrm{m}$; PDMS $100 \mu \mathrm{m}$ and PDMS/DVB, $65 \mu \mathrm{m}$; Supelco, Bellafonte, PA, USA) were used to compare the analyte extraction efficiencies.

\subsection{Instrumental and Chromatographic Conditions}

An Agilent 7820A gas chromatograph with flame ionization detector (FID) equipped with a split/splitless injector and an Agilent DB-5 capillary column $(30 \mathrm{~m} \times 0.25 \mathrm{~mm} \times 0.25 \mu \mathrm{m}$; Santa Clara, 
CA, USA) was used to optimize the method as well as to compare it with commercial fibers. On the other hand, a Shimadzu GC-MS QP2010 Plus equipped with a split/splitless injector (Kyoto, Japan) containing a Zebron ZB-5MS capillary column $(30 \mathrm{~m} \times 0.25 \mathrm{~mm} \times 0.25 \mu \mathrm{m}$; Torrance, CA, USA) was used to obtain the analytical parameters of merit. The GC-MS and GC/FID was operated at the same conditions for injection and the columns temperature programs. The injection was performed in splitless mode at $260^{\circ} \mathrm{C}$ for $15 \mathrm{~min}$. The column temperature program consisted of maintaining the oven at $80^{\circ} \mathrm{C}$ for $1 \mathrm{~min}$ and then increasing it $6^{\circ} \mathrm{C} \mathrm{min}-1$ to $300^{\circ} \mathrm{C}$ which was maintained for $10 \mathrm{~min}$. The transfer line temperature, the ion source temperature and the electron impact ionization (EI) mode of the GC-MS were set at $280,250^{\circ} \mathrm{C}$, and $70 \mathrm{eV}$, respectively. Helium was used as the carrier gas at a flow rate of $1.0 \mathrm{~mL} \mathrm{~min}^{-1}$. The PAHs were determined in selected ion monitoring (SIM) mode and the mass/charge $(\mathrm{m} / \mathrm{z}$ ) ratios employed are shown in Table 1 . The $\mathrm{m} / \mathrm{z}$ values in bold were used for the quantitative determination of the analytes.

Table 1. The $\mathrm{m} / \mathrm{z}$ values used for the determination of PAHs by GC-MS (values in bold were used for the quantification of the analytes).

\begin{tabular}{cc}
\hline Analytes & $\mathbf{m} / \mathbf{z}$ \\
\hline acenaphthylene & $\mathbf{1 5 2}, 153,151$ \\
fluorene & $\mathbf{1 6 6}, 165,167$ \\
phenanthrene & $\mathbf{1 7 8}, 176,179$ \\
anthracene & $\mathbf{1 7 8}, 179,176$ \\
pyrene & $\mathbf{2 0 2}, 203,200$ \\
benzo[a]anthracene & $\mathbf{2 2 8}, 226,229$ \\
chrysene & $\mathbf{2 2 8}, 226,229$ \\
benzo[b]fluoranthene & $\mathbf{2 5 2}, 250,126$ \\
benzo[k]fluoranthene & $\mathbf{2 5 2}, 250,126$ \\
benzo[a]pyrene & $\mathbf{2 5 2}, 250,126$ \\
\hline
\end{tabular}

\subsection{Preparation of Diatomaceous Earth Fibers}

The diatomaceous earth dust came from the disposal reservoir of a brewery, where this material is used for the filtration and clarification of beer (Santa Catarina, Brazil). Due to its high porosity, the material presents a high degree of saturation with organic matter from the treatment of beer. Thus, a heat treatment is required [20], not only to eliminate the residues originated from the beer filtration but to ensure that all of the organic matter adhered to the material is removed. The diatomaceous earth, after the thermal treatment, was sieved to obtain homogeneous particle size ( $<200$ mesh). The diatomaceous earth was adhered on a $1 \mathrm{~cm}$ nitinol wire using epoxy glue. Then, the new fiber was inserted into the heating block at $180^{\circ} \mathrm{C}$ for $90 \mathrm{~min}$, resulting in a final phase thickness of approximately $40 \mu \mathrm{m}$. The fiber was then conditioned at $240{ }^{\circ} \mathrm{C}$ for $90 \mathrm{~min}$ in a GC injection port. The fiber lifetime was verified during the study by comparing the responses of the chromatographic areas of the analytes to the optimum extraction condition at a concentration of $5 \mu \mathrm{g} \mathrm{L}^{-1}$. Fibers were used while the extraction efficiency did not present a reduction greater than $10 \%$.

\subsection{Optimization of SPME Procedure}

The optimization of the extraction conditions for the diatomaceous earth fiber was performed by multivariate procedures. A central composite design involving 11 experiments with triplicate at the central point was carried out. In the optimization strategy the extraction temperature ranged from 30 to $80{ }^{\circ} \mathrm{C}$ and the extraction time from 30 to $117 \mathrm{~min}$. The sodium chloride concentration $(0-20 \% \mathrm{~m} / \mathrm{v})$ was also evaluated, but in the univariate form. The extraction procedure consisted of immersing the SPME fiber directly in $25 \mathrm{~mL}$ of water sample spiked with $100 \mu \mathrm{g} \mathrm{L}^{-1}$ of each PAH contained in a $40 \mathrm{~mL}$ vial and kept under constant magnetic stirring at $1000 \mathrm{rpm}$. After the extraction, the fiber was immediately inserted into the GC injection port at $240{ }^{\circ} \mathrm{C}$ for $15 \mathrm{~min}$ for the thermal desorption of the analytes. The analysis was carried out by GC-FID in splitless mode. To obtain the response 
surface, the geometric mean of the areas of the chromatographic peaks obtained in each extraction using Statistica 8.0 software (Statsoft, USA) was used.

\subsection{Comparison of the Extraction Efficiencies Using Diatomaceous Earth and Commercial Fibers}

After the optimization of the analytical procedure, the diatomaceous earth was compared to commercial fibers (PDMS and PDMS/DVB) in terms of their efficiency in the extraction of the PAHs studied. The same procedure described at Section 2.4 was carried out but the ultrapure water was spiked with the analytes at a concentration of $5 \mu \mathrm{g} \mathrm{L}^{-1}$. The extractions were performed using one of the fibers at $80{ }^{\circ} \mathrm{C}$ for $70 \mathrm{~min}$. The chromatographic analysis was performed by GC-MS.

\subsection{Analytical Figures of Merit of the Method Developed}

River water spiked with five concentrations of each analyte ranging from 0.5 to $25.0 \mu \mathrm{g} \mathrm{L}^{-1}$ was prepared to build calibration curves which were used to calculate the linear coefficient of determination $\left(R^{2}\right)$. The lowest concentration on the analytical curve for each analyte which enabled measures with acceptable precision (RSD $<20 \%$ ) was adopted as limits of quantification (LOQs). The limits of detection (LODs) were obtained dividing the LOQ by 3.3. The precision and the accuracy of the method were evaluated by performing extractions using real water samples spiked with the analytes at $0.5 \mu \mathrm{g} \mathrm{L}^{-1}$. Precision was calculated as the relative standard deviation (RSD) obtained from spiked river water and accuracy was verified through the relative recovery of the analytes.

\section{Results and Discussion}

\subsection{Characterization of the Diatomaceous Fiber}

The diatomaceous earth samples used for the production of SPME fibers belong to the class Bacillariophyceae centricae and their color may vary from white to gray. The material consists mainly of silica, $\mathrm{SiO}_{2}(87-91 \%)$, alumina and ferric oxide [21].

Scanning electron microscopy (SEM) was carried out to characterize the surface morphology of the recycled diatomaceous earth. The images obtained at magnifications of 2000 and $4000 \times$ for the surface evaluation are shown in Figure 1 (A and B, respectively). An image of a cross-section of the proposed fiber was obtained at a magnification of $100 \times$ (Figure 1C). According to the SEM results, the morphology of the material shows a high porosity which facilitated the physical processes involving the sorption of the analytes.

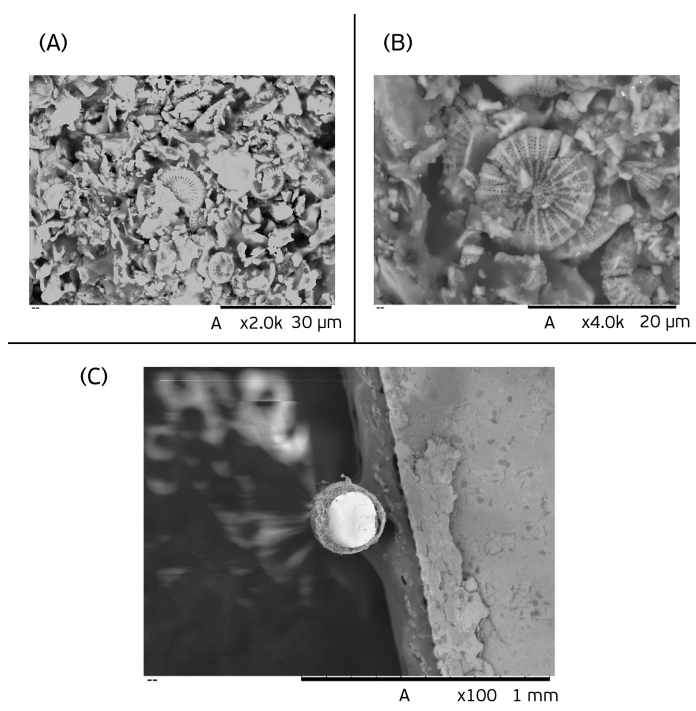

Figure 1. SEM micrographs obtained with the biosorbent fiber at magnifications of (A) $2000 \times$ and (B) $4000 \times$, and a cross-section of the proposed fiber (C) at a magnification of $100 \times$. 
FTIR spectroscopy was carried out to identify the functional groups in the sorbent. The FTIR spectrum obtained from the material previously conditioned at $240^{\circ} \mathrm{C}$ is illustrated in Figure 2. A broad peak at $\sim 3400 \mathrm{~cm}^{-1}$ corresponds to the $\mathrm{O}-\mathrm{H}$ bonds of silanol groups. Two intense peaks between $\sim 1200$ and $1080 \mathrm{~cm}^{-1}$ were assigned to the asymmetric stretching of the $\mathrm{Si}-\mathrm{O}-\mathrm{Si}$ siloxane groups and one at $\sim 790 \mathrm{~cm}^{-1}$ is related to the $\mathrm{Si}-\mathrm{O}-\mathrm{Si}$ vibrations attributed to mesoporous silicas. At $\sim 475 \mathrm{~cm}^{-1}$, a peak related to $\mathrm{O}-\mathrm{Si}-\mathrm{O}$ vibration was present. Lastly, the peak at $\sim 1600 \mathrm{~cm}^{-1}$ refers to the angular deformation of the adsorbed water molecules.

Thermogravimetric analysis was conducted to identify if there was any organic material present in the sample and since no mass loss was observed the material can be characterized as thermally stable (data not shown). This result was already expected, since the sorbent comes from inorganic material.

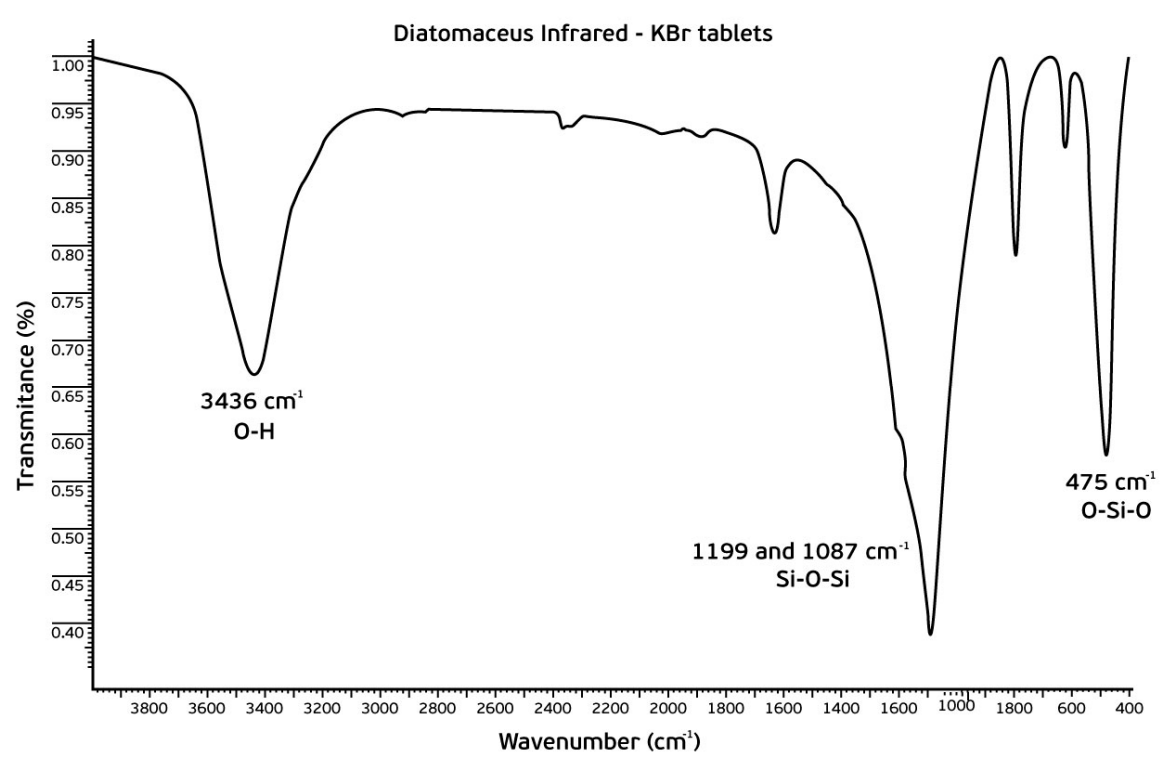

Figure 2. FTIR spectrum of the biosorbent, previously conditioned at $240{ }^{\circ} \mathrm{C}$.

\subsection{Optimization of DI-SPME Extraction Procedure}

The extraction conditions that can influence the SPME efficiency were optimized using the diatomaceous earth fiber. The response used to feed the software Statistica 8.0 was the geometric means of the chromatographic peak areas of the analytes. The response surfaces obtained for the biosorbent fiber are shown in Figure 3.
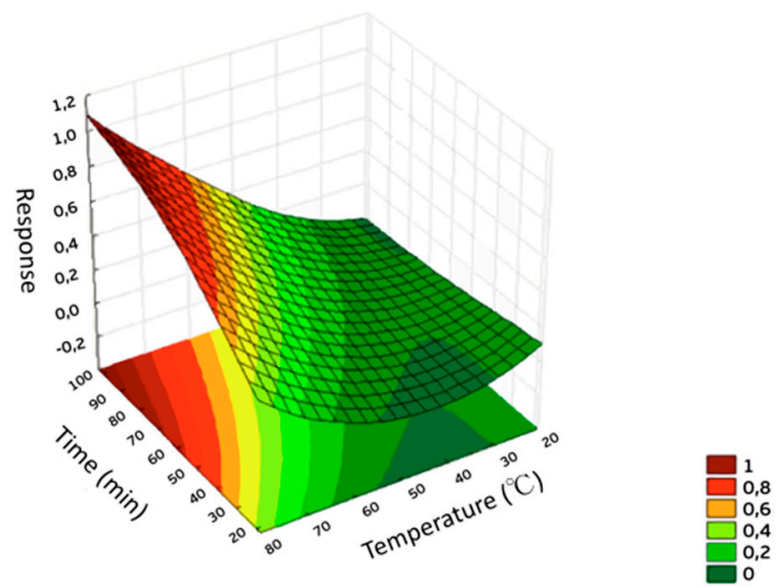

Figure 3. Response surface obtained for the optimization of DI-SPME procedure using biosorbent fiber (diatomaceous earth). 
The optimum extraction conditions selected for the proposed fiber were reached using an extraction time of $70 \mathrm{~min}$ at $80{ }^{\circ} \mathrm{C}$. The addition of salt was also studied as it is known to lead to the salting-out effect. However, the use of small amounts of salt caused fiber damage and so no salt was added in the extractions.

\subsection{Comparison between the Extraction Efficiencies of the Biosorbent and Commercial Coatings}

A comparison between the extraction efficiencies using the proposed fiber and commercial fibers (PDMS/DVB and PDMS) was performed. The conditions for the extractions using commercial fibers were optimized (data not shown) as extraction time of $70 \mathrm{~min}$ at $80^{\circ} \mathrm{C}$. These values are much closed to those mentioned in the literature (extractions of $60 \mathrm{~min}$ at $70^{\circ} \mathrm{C}$ ) [22-24]. Figure 4 shows this comparison through bar graph using normalized peak area and considering the film thickness of each fiber. The normalization of peak areas for each analyte was made using the highest chromatographic peak areas as $100 \%$ for each analyte.

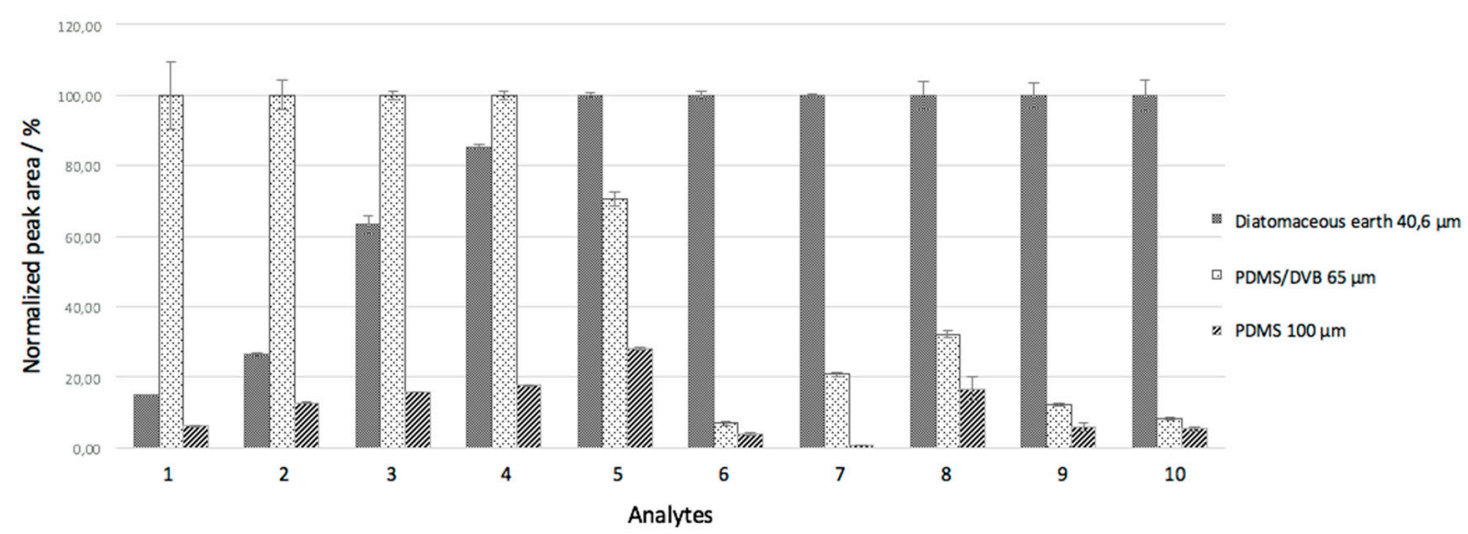

Figure 4. Comparison of extraction efficiencies of the biosorbent fiber, PDMS/DVB and PDMS coatings for determination of PAHs. Analytes: (1) acenaphtlylene; (2) fluorene; (3) phananthrene; (4) anthracene; (5) pyrene; (6) benzo[a]anthracene; (7) chrysene; (8) benzo[b]fluoranthene; (9) benzo[k]fluoranthene; and (10) benzo[a]purene.

It can be observed in Figure 4 that the extraction with the PDMS/DBV coating showed good performance for acenaphthylene, fluorene, phenanthrene, and anthracene, but for the other analytes the results were not as promising. The PDMS fiber gave values below 20\%, except for pyrene, and it is not efficient for this application. Taking this into account, the proposed fiber demonstrated very satisfactory performance for PAH extraction when compared to the commercial fibers, with the exception of acenaphthylene, fluorine, and phenanthrene.

In addition, reproducibility studies using two diatomaceous earth fibers were performed and the results showed no significant variation (data not shown). The repeatability obtained with the fibers was estimated comparing the results of the first extraction with those obtained after 115 extractions using the same fiber (data not shown). It was verified that there was no significant loss of extraction efficiency, confirming that the fiber produced with the biosorbent material can be used at least 115 times.

These data demonstrate the high potential for diatomaceous earth fiber as a sorbent candidate for SPME. Moreover, diatomaceous earth is biodegradable, natural, and renewable. In addition, its chemical composition provides numerous possibilities of chemical interaction with a wide range of compounds. Diatomaceous earth has a microporous structure, which facilitates the extraction of the analytes through a physical process (adsorption mechanism). 


\subsection{Validation Parameters}

Table 2 presents some analytical figures of merit obtained in this study. The linear coefficient of determination $\left(\mathrm{R}^{2}\right)$ values were $>0.95$, which indicates a good linear fit. The LOD and LOQ values were satisfactory based on those obtained in other studies.

Table 2. The linear range, linear equation, linearity, and limits of detection and quantification for the method developed using diatomaceous earth coating.

\begin{tabular}{|c|c|c|c|c|c|}
\hline Analyte & $\begin{array}{c}\text { LOD } \\
\left(\mu \mathrm{g} \mathrm{L}^{-1}\right)\end{array}$ & $\begin{array}{c}\mathrm{LOQ} \\
\left(\mu \mathrm{g} \mathrm{L}^{-1}\right)\end{array}$ & $\begin{array}{l}\text { Linear Range } \\
\left(\mu g L^{-1}\right)\end{array}$ & Linear Equation & $\mathbf{R}$ \\
\hline Acenaphthylene & 0.16 & 0.49 & $0.49-25$ & $y=66,956 x-30,445$ & 0.9890 \\
\hline Fluorene & 0.17 & 0.50 & $0.50-25$ & $y=87,809 x-54,517$ & 0.9911 \\
\hline Phenanthrene & 0.14 & 0.42 & $0.42-25$ & $y=326,565 x-245,240$ & 0.9777 \\
\hline Anthracene & 0.11 & 0.33 & $0.33-25$ & $y=364,057 x-339,574$ & 0.9598 \\
\hline Pyrene & 0.15 & 0.50 & $0.50-25$ & $y=979,497 x-935,649$ & 0.9914 \\
\hline benzo[a]anthracene & 0.03 & 0.10 & $0.10-25$ & $y=506,040 x-544,597$ & 0.9832 \\
\hline Chrysene & 0.14 & 0.42 & $0.42-25$ & $y=691,902 x-796,526$ & 0.9592 \\
\hline benzo[b]fluoranthene & 0.06 & 0.17 & $0.17-25$ & $y=158,587 x-50,481$ & 0.9990 \\
\hline benzo[k]fluoranthene & 0.11 & 0.33 & $0.33-25$ & $y=431,634 x-806,517$ & 0.9848 \\
\hline benzo[a]pyrene & 0.15 & 0.46 & $0.46-25$ & $y=295,450 x-567,387$ & 0.9667 \\
\hline
\end{tabular}

Precision was evaluated in terms of intra-day repeatability $(n=3)$ and inter-day reproducibility $(n=9)$ using samples spiked at the lowest level for each analyte. The results obtained are shown in Table 3. It can be observed that the intra-day and inter-day precision for diatomaceous earth fiber presented values of RSD $<15 \%$ and $<17 \%$, respectively. Relative recovery showed results between $83 \%$ and $100 \%$, confirming the accuracy of the method.

Table 3. Relative recovery of analytes and precision (inter- and intra-day) for the extraction of PAHs from spiked river water samples.

\begin{tabular}{|c|c|c|c|c|}
\hline Analyte & $\begin{array}{l}\text { Spiked Concentration } \\
\left(\mu \mathrm{g} \mathrm{L}^{-1}\right)\end{array}$ & $\begin{array}{l}\text { Relative Recovery (\%) } \\
\qquad(n=3)\end{array}$ & $\begin{array}{c}\text { RSD, } \\
\text { Intra-Day (\%) } \\
(n=3)\end{array}$ & $\begin{array}{c}\text { RSD, } \\
\text { Inter-Day (\%) } \\
(n=3)\end{array}$ \\
\hline acenaphthylene & 0.5 & 100 & 5 & 10 \\
\hline fluorene & 0.5 & 83 & 15 & 10 \\
\hline phenanthrene & 0.5 & 97 & 10 & 13 \\
\hline anthracene & 0.5 & 93 & 13 & 3 \\
\hline pyrene & 0.5 & 92 & 2 & 6 \\
\hline benzo[a]anthracene & 0.5 & 94 & 2 & 6 \\
\hline chrysene & 0.5 & 96 & 2 & 6 \\
\hline benzo[b]fluoranthene & 0.5 & 90 & 15 & 17 \\
\hline benzo[k]fluoranthene & 0.5 & 97 & 15 & 17 \\
\hline benzo[a]pyrene & 0.5 & 93 & 7 & 17 \\
\hline
\end{tabular}

The selectivity of the proposed method was confirmed by the absence of peaks in the retention time of the target analytes when chromatograms of the extract were obtained from the river water sample without the addition of the analytes. The only exceptions were pyrene, chrysene, and benzo[a]pyrene, but these peaks were not quantifiable. Figure 5 shows the chromatograms obtained for samples of spiked river water $\left(10 \mu \mathrm{g} \mathrm{L}^{-1}\right)$ and non-spiked river water. 


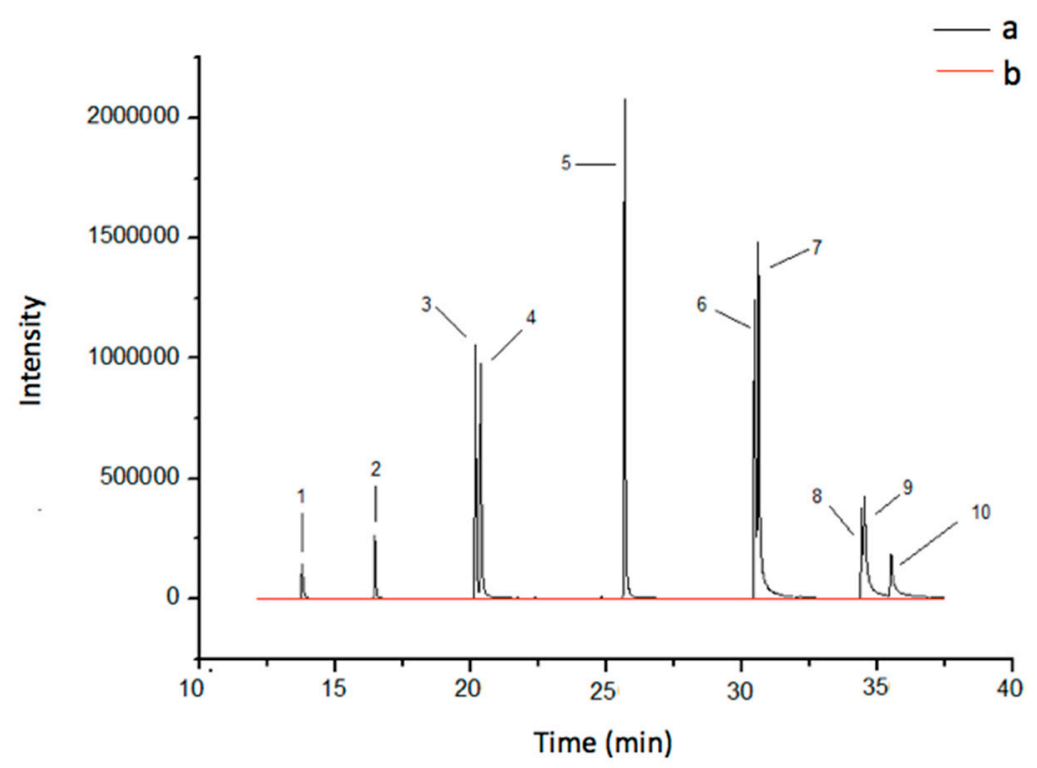

Figure 5. Chromatograms (GC-MS) obtained from a river water sample spiked at $10 \mu \mathrm{g} \mathrm{L}^{-1}$ (a) and non-spiked river water sample (b). Elution order: (1) acenaphtlylene; (2) fluorene; (3) phananthrene; (4) anthracene; (5) pyrene; (6) benzo[a]anthracene; (7) chrysene; (8) benzo[b]fluoranthene; (9) benzo[k]fluoranthene; and (10) benzo[a]pyrene.

\section{Conclusions}

In this study, the use of a recycled diatomaceous earth as extractive phase for SPME fiber demonstrated suitable results in comparison to widely used commercial fibers. The production of the biosorbent fiber is simple and the fibers can be reused several times. The separation and detection of the analytes by GC-MS is effective and enables the determination of PAHs in accordance with current Brazilian legislation. The proposed method using the biosorbent achieved good results of parameters of merit. The method is of low cost, because the natural sorbent can be reused in numerous extractions and is widely applicable because the material is easily obtainable.

Author Contributions: All of the authors participated in the same proportion.

Funding: Conselho Nacional de Desenvolvimento Científico e Tecnológico (CNPq), process number 303892/2014-5. Coordenação de Aperfeiçoamento de Pessoal de Nivel Superior—Brasil (CAPES) —Finance Code 001.

Acknowledgments: The authors are grateful to the Brazilian governmental agency "Conselho Nacional de Desenvolvimento Científico e Tecnológico (CNPq) and Coordenação de Aperfeiçoamento de Pessoal de Nível Superior" for the financial support which made this research possible.

Conflicts of Interest: The authors declare no conflict of interest.

\section{References}

1. Benson, R.; Conerly, O.D.; Sander, W.; Batt, A.L.; Boone, J.S.; Furlong, E.T.; Glassmeyer, S.T.; Kolpin, D.W.; Mash, H.E.; Shenck, K.M.; et al. Human health screening and public health significance of contaminants of emerging concern detected in public water supplies. Sci. Total Environ. 2017, 579, 1643-1648. [CrossRef] [PubMed]

2. Pal, A.; He, Y.; Jakel, M.; Reinhard, M.; Gin, K.Y. Emerging contaminants of public health significance as water quality indicator compounds in the urban water cycle. Environ. Int. 2014, 71, 46-62. [CrossRef] [PubMed]

3. Heleno, F.F.; Lima, A.C. Evaluation of analytical methods for BTEX analysis in water using extraction by headspace (HS) and solid phase microextraction (SPME). Quim. Nova 2010, 33, 329-336. [CrossRef]

4. Hong, W.F.; Jia, H.; Li, Y.F. Polycyclic aromatic hydrocarbons (PAHs) and alkylated PAHs in the coastal seawater, surface sediment and oyster from Dalian, Northeast China. Ecotoxicol. Environ. Saf. 2016, 128, 11-20. [CrossRef] [PubMed] 
5. Slezakva, K.; Castro, D.; Delerue-Matos, C. Impact of vehicular traffic emissions on particulate-bound PAHs: Levels and associated health risks. Atmos. Res. 2013, 127, 141-147. [CrossRef]

6. Cristale, J.; Silva, F.S.; Zocolo, G.J.; Marchi, M.R.R. Influence of sugarcane burning on indoor/outdoor PAH air pollution in Brazil. Environ. Pollut. 2012, 169, 210-216. [CrossRef] [PubMed]

7. Dat, N.D.; Chang, M.B. Review on characteristics of PAHs in atmosphere, anthropogenic sources and control technologies. Sci. Total Environ. 2017, 31, 682-693. [CrossRef] [PubMed]

8. Siritham, C.; Thammakhet-Buranacha, C. A preconcentrator-separator two-in-one online system for polycyclic aromatic hydrocarbons analysis. Talanta 2017, 15, 573-582. [CrossRef] [PubMed]

9. Li, Z.; Ma, R.; Bai, S.; Wang, C.; Wang, Z. A solid phase microextraction fiber coated with graphene-poly9ethylene glycol) composite for the extraction of volatile aromatic compounds from water samples. Talanta 2014, 119, 498-504. [CrossRef] [PubMed]

10. Laopongsit, W.; Srzednicki, G.; Craske, J. Preliminary study of solid phase micro-extraction (SPME) as a method for detecting insect infestation in wheat grain. J. Stored Prod. Res. 2014, 59, 88-95. [CrossRef]

11. Lord, H.; Pawliszyn, J. Evolution of solid-phase microextraction technology. J. Chromatogr. A 2000, 885, 153-193. [CrossRef]

12. Dias, A.N.; Simão, V.; Merib, J.; Carasek, E. Cork as a new (green) coating for solid-phase microextraction: Determination of polycyclic aromatic hydrocarbons in water samples by gas chromatography-mass spectrometry. Anal. Chim. Acta 2013, 772, 33-39. [CrossRef] [PubMed]

13. Carasek, E.; Merib, J. Membrane-based microextraction techniques in analytical chemistry: A review. Anal. Chim. Acta 2015, 23, 8-25. [CrossRef] [PubMed]

14. Pawliszyn, J. Handbook of Solid Phase Microextraction; Chem. Ind. Press: Beijing, China, 2009.

15. Tsao, Y.U.; Wang, Y.C.; Wu, S.F.; Ding, W.H. Microwave-assisted headspace solid-phase microextraction for the rapid determination of organophosphate esters in aqueous samples by gas chromatography-mass spectrometry. Talanta 2011, 84, 406-410. [CrossRef] [PubMed]

16. Ahmadi, M.; Elmongy, H.; Madrakian, T.; Abdel-Rehim, M. Nanomaterials as sorbents for sample preparation in bioanalysis: A review. Anal. Chim. Acta 2017, 15, 1-21. [CrossRef] [PubMed]

17. Do Carmo, S.; Merib, J.; Dias, A.N.; Stolberg, J.; Budziak, D.; Carasek, E. A low-cost biosorbent-based coating for the highly sensitive determination of organochlorine pesticides by solid-phase microextraction and gas chromatography-electron capture detection. J. Chromatogr. A 2017, 1525, 23-31. [CrossRef] [PubMed]

18. Suterio, N.G.; do Carmo, S.N.; Budziak, D.; Merib, J.; Carasek, E. Use of a Natural Sorbent as Alternative Solid-Phase Microextraction Coating for the Determination of Polycyclic Aromatic Hydrocarbons in Water Samples by Gas Chromatography-Mass Spectrometry. J. Braz. Chem. Soc. 2018, 29. [CrossRef]

19. Silveira, C.B.; Goulart, M.R. Methodologies for the reuse of the diatomaceous earth residue, from filtration and clarification of beer. Quim. Nova 2011, 34, 625-629.

20. Souza, G.P.; Filgueira, M. Characterization of natural diatomaceous composite material. Ceramica 2003, 49, 40-43. [CrossRef]

21. Othmer, K. Encyclopedia of Chemical Technology; Wiley: New York, NY, USA, 1993; p. 108.

22. Menezes, H.C.; Paulo, B.P.; Paiva, M.J.N.; Barcelos, S.M.R.; Macedo, D.F.D.; Cardeal, Z.L. Determination of polycyclic aromatic hydrocarbons in artisanal cachaça by DI-CF-SPME-GC/MS. Microchem. J. 2015, 118, 272-277. [CrossRef]

23. Aguinaga, N.; Campillo, N.; Vinas, P.; Hernández-Córdoba, M. Determination of 16 polycyclic aromatic hydrocarbons in milk and related products using solid-phase microextraction coupled to gas chromatography-mass spectrometry. Anal. Chim. Acta 2007, 23, 285-290. [CrossRef] [PubMed]

24. Segura, A.; Sánchez, V.H.; Marqués, S.; Molina, L. Insights in the regulation of the degradation of PAHs in Novosphingobium sp. HR1a and utilization of this regulatory system as a tool for the detection of PAHs. Sci. Total Environ. 2017, 590, 381-393. [CrossRef] [PubMed]

(C) 2018 by the authors. Licensee MDPI, Basel, Switzerland. This article is an open access article distributed under the terms and conditions of the Creative Commons Attribution (CC BY) license (http:/ / creativecommons.org/licenses/by/4.0/). 